The Double ABCX Model of Family Adaptation in Families of a Child with an Autism Spectrum Disorder Attending an Australian Early Intervention Service

This is the author's personal copy of the final accepted manuscript. Please see below for the final published manuscript:

Paynter, J., Riley, E., Beamish, W., Davies, M., \& Milford, T. (2013). The double ABCX model of family adaptation in families of a child with an autism spectrum disorder attending an Australian early intervention service. Research in Autism Spectrum Disorders, 7(10), 1183-1195. doi: http://dx.doi.org/10.1016/j.rasd.2013.07.006 


\begin{abstract}
It is well established that families caring for a child with an Autism Spectrum Disorder (ASD) experience increased psychological distress compared to other families (e.g., BakerEriczén, Brookman-Frazee, \& Stahmer, 2005; Lee et al., 2009). However, little research has captured the range of variables linked to family outcomes, and research in the early childhood period has been largely atheoretical. The current study sought to investigate the applicability of the Double ABCX Model of Family Adaptation (McCubbin \& Patterson, 1983) in understanding the factors underlying family outcomes when children with ASD attend early intervention. Participants included 43 parents (18 males, 25 females) of children aged $2 \frac{1}{2}$ to 6 years $(M=49.35, S D=9.21$ months; 8 female, 35 male $)$ with ASD who were attending an autism-specific intervention service. Participants completed standardised questionnaire measures of constructs of the Double ABCX Model. As predicted by the model, family systems outcomes (individual, relationship, or family) were linked to symptom severity (challenging behaviour), pile-up demands, internal and external resources, appraisals, and active-avoidant coping styles. Level of ASD symptoms however, were not significantly linked to outcomes. Limitations, directions for future research, and practical implications are discussed.
\end{abstract}

Keywords: Autism; family adaptation; early intervention. 


\section{The Double ABCX Model of Family Adaptation in Families of a Child with an Autism Spectrum Disorder Attending an Australian Early Intervention Service}

\section{Introduction}

Autism Spectrum Disorders (ASD) include "classic" autism, Asperger Syndrome, and Pervasive Developmental Disorder-Not Otherwise Specified (Wray, Silove, \& Knott, 2005). These conditions share a characteristic triad of impairments in social interaction, language and communication, and restricted and repetitive behaviours and interests (APA, 2000). Recent research suggests ASDs affect as many as 1 in 88 children (Centers for Disease Control and Prevention., 2012) and early intervention has been the focus of both service provision and research (e.g., Charman \& Howlin, 2003; Lord et al., 2005). To date, little research has focused on family adaptation to having a child with ASD during this early period prior to schooling. Family adaptation, a core element of family systems theory, refers to the family's ability to manage when change and stress occur (Olson, Sprenkle, \& Russell, 1979; Turnbull \& Turnbull, 2001).

Caring for a child with an ASD has been associated with increased psychological distress across the family system (e.g., Baker-Ericzén et al., 2005; Eisenhower, Baker, \& Blacher, 2005; Konstantareas, Homatidis, \& Plowright, 1992; Lee et al., 2009). Psychological distress may include increased stress, parenting stress, depression or anxiety symptoms, reduced marital satisfaction, or negative impact on family functioning. Mothers and fathers of children with ASD report significantly elevated levels of child and parent-related stress compared to parents of typically developing children (Baker-Ericzén et al., 2005; Lee et al., 2009). Moreover, families report increased stress compared to families with a child with intellectual impairment (Eisenhower et al., 2005; Konstantareas et al., 1992), Down syndrome (Eisenhower et al., 2005; 
Sanders \& Morgan, 1997), or a chronic physical illness such as cystic fibrosis (Bouma \& Schweitzer, 1990) or cerebral palsy (Eisenhower et al., 2005). Mothers of children with ASD are also more likely to experience poorer psychological well-being (e.g., depression symptoms) and coping compared to mothers of children with Down syndrome, fragile X, cerebral palsy, and developmental delay (Abbeduto et al., 2004; Blacher \& McIntyre, 2006; Eisenhower et al., 2005; Estes et al., 2009). Parents of children with ASD have been reported to experience reduced marital satisfaction (e.g., Higgins, Bailey, \& Pearce, 2005; Rodrigue, Morgan, \& Geffken, 1990). However, some families who have a child with ASD adapt well with some studies finding scores on measures of family functioning (e.g., conflict, family adaptability) in the healthy range (Rodrigue, et al., 1990; Sanders \& Morgan, 1997). In order to identify families at risk of psychological distress so as to provide targeted support, it is important to understand what factors may underlie these differences in family adaptation outcomes (psychological distress vs. well-being) in families who are caring for a child with ASD.

An emerging body of literature suggests that the Double ABCX Model of Family Adaptation (McCubbin \& Patterson, 1983) provides a robust framework for conceptualising and organising variables related to psychological distress. This model regards an individual family's experience of crisis, stress, and subsequent adaptation as a dynamic and ongoing process (Redington, Kysela, \& McDonald, 1995). As presented in Figure 1, the adaptation process is affected by the initial stressor (A) and the pile-up of additional demands or stressors (aA), and is affected by the family and individual's internal (B) and external (bB) resources, their response to the stressor (C), and availability of effective coping strategies (cC). Adaptation and outcomes occur at a range of levels (X) including individual, relationship, and family. When this model has been applied to families of children with ASD, severity of stressor relates to the level of ASD 
symptomatology, and/or challenging behaviour. Pile-up demands refer to additional demands placed on the family such as financial strain, stressful life events such as death, moving house, and any other stressors which may occur. Resources refer to both internal attributes such as selfesteem, "hardiness," or self-efficacy, and external supports such as social networks. Appraisals of stressor include the family's positive and negative perceptions of having a child with ASD. Coping strategies refer to the tactics used by a family to cope with the aggregation of stressors.

\section{[Insert Figure 1 here]}

Three studies could be located in the literature that specifically investigated the Double ABCX Model of Family Adaptation and childhood ASD in the USA (Bristol, 1987; Manning et al., 2010; Stuart \& McGrew, 2009). Bristol (1987) first used the double ABCX model to investigate adaptation in mothers of children with autism or communication impairment aged 210 years and found the model significantly predicted adaptation (canonical correlation of .67) overall, and accounted for a significant proportion of the variance in quality of parenting (55\%), depressive symptoms (33\%), and marital adjustment (53\%). Stuart and McGrew (2009) investigated family outcomes after receiving a diagnosis of ASD. They found that a significant amount of the variance in individual (81\%), marital (51\%), and family (77\%) psychological distress was accounted for by the double ABCX model. Manning et al. (2010) investigated wellbeing and psychological distress in racially-diverse families with a school-aged child with an ASD and found a significant amount of the variance in family functioning (28\%) and parental distress (46\%) was accounted for by this model. Two additional Australian studies (Pakenham, Samios, \& Sofronoff, 2005; Pakenham, Sofronoff, \& Samios, 2004) supported the utility of the model for framing and understanding adaptation processes in mothers of youth with Asperger Disorder. Taken together, these studies support the utility of the double ABCX model in 
understanding and organising the range of factors that may influence family adjustment and outcomes when caring for a child with ASD.

To date, research around family outcomes during the early intervention period, has been predominantly atheoretical, has failed to use models of family adaptation such as the Double ABCX Model, and has focused either exclusively or predominantly on mothers (e.g., BakerEriczén et al., 2005; Eisenhower et al., 2005; Estes et al., 2009). In all, family adaptation and psychological distress during the early intervention period is poorly understood.

The early intervention period is a key stage of development for children with ASD. This period offers the best opportunity for gains for children due to neural plasticity at a younger age (e.g., Dawson, 2008) with a recent review showing greater gains when intervention is started at a younger age (Makrygianni \& Reed, 2010). Moreover, family adaptation and psychological distress is important to investigate, as within autism specifically, greater parenting stress has been linked to reduced efficacy of interventions (e.g., Osborne, McHugh, Saunders, \& Reed, 2008a; Robbins, Dunlap, \& Plienis, 1991). Furthermore, increased psychological distress, including maternal depression and marital discord has been more extensively linked to poorer child outcomes such as increased challenging behaviour, as well as to reduced efficacy of parenting interventions in the broader literature on typically developing children (e.g., Goodman et al., 2011; Kelly, 2000; Reyno \& McGrath, 2006). Thus, understanding family adaptation during the early intervention period is important for both better supporting families during this critical period and for maximising outcomes for their children.

\subsection{Factors Influencing Parental Well-being and Psychological Distress}

1.1.1. Symptom severity. Two aspects of symptom severity have been explored in previous research; these are ASD symptoms, and challenging behaviour. Several studies have found that 
the severity of a child's ASD symptoms is related to greater parental stress (e.g., Abbeduto et al., 2004; Manning et al., 2010; Osborne, McHugh, Saunders, \& Reed, 2008b). In addition, children with ASD are also more vulnerable to developing challenging behaviour than other groups such as children who are typically developing or have other disabilities (e.g., Blacher \& McIntyre, 2006; Eisenhower et al., 2005). Child challenging behaviour has been linked to elevated parenting stress and elevated levels of parental psychological distress (Benson, 2010; Estes et al., 2009), as well as greater negative impact on families (Eisenhower et al., 2005; Manning et al., 2010). Where both ASD symptoms and challenging behaviour have been investigated as predictors of parent outcomes within the same study, challenging behaviour tends to be more strongly related to poorer outcomes (e.g., Benson, 2010; Manning et al., 2010).

1.1.2. Pile-up demands. Caring for a child with ASD is associated with a complex network of additional family stressors (Randall \& Parker, 1999). Many families, in addition to the needs of caring for a child with ASD, report a confluence of stressors (pile-up demands) such as experiencing financial hardship due to the costs of therapies, reduced capacity to work, and increased cost of other activities such as childcare and extracurricular activities (Ramisch, 2010). Previous research has linked the pile-up of other stressors as independent predictors for maternal depression (Bristol, 1987; Stuart \& McGrew, 2009), poorer marital adjustment (Bristol, 1987; Stuart \& McGrew, 2009) and increased family psychological distress (Stuart \& McGrew, 2009). Yet one study failed to find a link between other life stressors affecting the family and family functioning or parenting distress (Manning et al., 2010). However, this last study used a different measure of pile-up demands, The Life Stress scale from the Parenting Stress Index (Abidin, 1995a), whereas Bristol (1987) and Stuart and McGrew both used measures 
incorporating modified versions of the Social Readjustment Rating Scale (Holmes \& Rahe, 1967).

1.1.3. Internal resources. Internal resources such as self-esteem (Weiss, 2002), optimism (Baker, Blacher, \& Olsson, 2005), and self-efficacy (Hastings \& Brown, 2002) have been linked to better parent psychological well-being. Weiss (2002) found that mothers of children with autism who reported higher self-esteem combined with a high level of social support reported lower levels of depression than those with lower self-esteem and fewer social supports. In addition, self-efficacy has been found to mediate the effect of child challenging behaviour on anxiety and depression in mothers, but not in fathers (Hastings \& Brown, 2002).

1.1.4. External resources. Social support is an external resource linked to lower family distress, and more effective family adaptation. In their review of the literature on social support and maternal stress, Boyd (2002) found that informal social supports including networks of family, friends, neighbours, and other parents of children with ASD can mitigate maternal stress. Moreover, among mothers of children and youth with ASD, informal social supports have also been linked to increased life satisfaction and psychological well-being, and reduced parenting stress (Ekas, Lickenbrock, \& Whitman, 2010). Conversely, low levels of social support have been linked to higher levels of psychological distress amongst members of a family with a child with ASD (Boyd, 2002; Weiss, 2002). Furthermore, greater social support has also been linked to better marital outcomes (Bristol, 1987) and better family adaptation (e.g., Manning et al., 2010; Stuart \& McGrew, 2009).

1.1.5. Appraisal of stressors. Family responses to stressors, such as symptom severity or additional life stressors (pile-up demands) have been found to be affected not only by the objective characteristics of events (e.g., severity of challenging behaviour), but by the way the 
family defines and understands situations. Responses can include both positive and negative appraisals of, for example, having a child with ASD. Stuart and McGrew (2009) found that greater endorsement of negative appraisals was associated with higher levels of psychological distress in the family system (individual, marital, and family) when a child had a recent ASD diagnosis. Similarly, Bristol (1987) found that mothers of children with autism who negatively appraised caring for a child with ASD demonstrated poorer parenting (as rated by an observer), more depression, and greater marital maladjustment.

With respect to positive appraisals, findings are mixed. Stuart and McGrew (2009) did not find significant links between greater positive appraisals (e.g., finding benefits in having a child with ASD), and family psychological distress in parents of children with autism. In contrast, other studies have found that higher reports of positive perceptions have been linked to lower levels of depression in parents of preschoolers with autism (Hastings, Kovshoff, Ward, et al., 2005), and lower parenting stress in parents of school-age children with autism (Manning et al., 2010). Thus, the way a family defines and understands living with a child with autism may affect the level of psychological distress experienced in the family.

1.1.6. Coping strategies. A growing body of research suggests that the behavioural or cognitive strategies (i.e., coping strategies) employed by family members affects the level of psychological distress they experience. Hastings, Kovshoff, and Brown, et al. (2005) investigated the coping strategies used by parents of preschool and school-age children with autism and found that four reliable dimensions of coping emerged. Dimensions include activeavoidance coping (e.g., use alcohol/drugs to get through, blame myself for things that happen), problem-focused coping (e.g., take action to make the situation better), positive coping (e.g., 
reframing in a positive light), and religious/denial coping (e.g., finding comfort in religious beliefs).

Avoidant coping styles have been associated with greater parenting stress, and more anxiety and depression symptoms, and a greater negative impact on family (Hastings, Kovshoff, \& Brown, et al., 2005; Stuart \& McGrew, 2009). Greater use of positive coping has been associated with reduced parental distress such as lower levels of depression in parents (Hastings, Kovshoff, \& Brown, et al., 2005; Manning et al., 2010). Findings for religious/denial coping are mixed. One study found an association with more depression in both mothers and fathers, and additionally with anxiety in fathers (Hasting, Kovshoff, \& Brown, et al., 2005), whereas another found that seeking spiritual support was associated with lower reports of parenting stress (Manning et al., 2010). Problem-focused coping has not been linked to parent outcomes (Hastings, Kovshoff, \& Brown, et al., 2005; Stuart \& McGrew, 2009).

\subsection{Aims and Hypotheses}

The aim of the present study was to investigate the usefulness of the Double ABCX Model as a framework for better understanding the factors that lead to or reduce the psychological distress of mothers and fathers of young children (21/2 to 6 years) with ASD attending an Australian autism-specific early intervention service. Based on the above, it was hypothesised that higher symptom severity (ASD symptoms and/or challenging behaviour), greater pile-up of life demands (additional stressful events), negative appraisals of caring for a child with ASD, and greater use of active-avoidant coping styles would be linked with increased psychological distress across each level of the family system (individual, relationship, and family). 


\section{Method}

\subsection{Participants and Procedure}

This study was conducted within the AEIOU Foundation, a not-for-profit organisation in Queensland, Australia that provides intensive early intervention within a full-time centre-based program to children from age $2 \frac{1}{2}$ to 6 years who have been diagnosed with ASD (Paynter, Scott, Beamish, Duhig, \& Heussler, 2012). Ethical approval was granted through the Griffith University Human Research Ethics Committee, approval number EBL/44/10/HREC. At the time of recruitment (2010), a total of 168 families were enrolled in the program across nine centres in Queensland. Participants were recruited through information sessions, flyers, and telephone calls. In total, 110 families contacted the first author with an interest in participating in the study and were either mailed or given questionnaire package in face-to-face sessions. The questionnaire package consisted of 288 questions measuring constructs of the double $\mathrm{ABCX}$ model as well as demographic information; it took approximately 60 minutes to complete. To be included in the study, caregivers had to confirm that they had a child currently attending AEIOU (an early intervention service) which required a formal independent diagnosis of an ASD by a medical practitioner. Of the 110 interested families, 43 participants (25 mothers and 18 fathers) completed and returned the survey, a response rate of $39 \%$, which is consistent with other Australian research with parents of children with ASD (Higgins et al., 2005). The group of families participating in the study appeared representative of families participating in the service, based on available demographic data drawn from a three year evaluation (Paynter, Riley, Beamish, Heussler, \& Scott, 2013) of all participating families at one Brisbane site. Demographic data available included child age $(M=4.04$ years, $S D=.82)$, child gender ratio 
(83.8\% male), diagnosis (64\% Autistic Disorder), and severity of ASD symptoms as indicated by scores on the Social Communication Questionnaire $(M=17.98, S D=4.71)$.

\subsection{Measures}

2.2.1. Demographics. A demographic questionnaire was included to assess current characteristics of the family's background, including ethnicity, household and social environment, as well as information about the child's diagnosis.

2.2.2. Symptom severity (A). Two measures were used to assess the severity of child symptoms including ASD-specific symptoms and associated behavioural difficulties. In keeping with a previous study into parental outcomes of having a child with ASD, which also used the ABCX model (viz., Manning et al., 2010), the Social Communication Questionnaire (SCQ) current form (Rutter, Bailey, \& Lord, 2003) was used to assess the severity of ASD symptoms. The SCQ generates a total score which ranges from 0 to 39 , has good internal validity for the total score $(\alpha=.90)$ as well as adequate item-total correlations in the range of .26 to .73 , with 23 of the 39 showing item-total correlations over .50 (Berument, Rutter, Lord, Pickles, \& Bailey, 1999). For this study, it showed poor internal consistency $(\alpha=.53)$; however, was retained based upon previous results as well as importance in answering the research question.

The Australian parent-rated version of the Strengths and Difficulties Questionnaire 4-10 years version (SDQ: Goodman, 1997) was used to assess the severity of behavioural symptoms. It is a 25 -item instrument which includes ratings for emotional symptoms, conduct problems, hyperactivity, peer problems, and prosocial behaviour. It is normed for children who are typically developing; however total scores have been used as an indicator of challenging behaviour in children with autism in previous research (e.g., Allik, Larsson, \& Smedje, 2006). 
The total problems score (a sum of the first four categories) was also used in the present study and showed adequate reliability $(\alpha=.73)$.

2.2.3. Pile-up demands (aA). A modified version of the Revised Social Readjustment Rating Scale (RSRRS: Hobson \& Delunas, 2001) was used to assess stressful life events. This measure was modified from a dichotomous yes/no and calculating totals from item weights, to participants being asked to rate 50 items on a 6 -point Likert scale $(0=$ not experienced to $5=$ experienced with extreme distress). A total score was calculated by summing the ratings across all items. This modification has previously been used with the original Social Readjustment Rating Scale (SRRS: Holmes \& Rahe, 1967) which has demonstrated adequate internal consistency $(\alpha=0.82-0.87)$ in studies into stress in parents of children with ASD (Bristol, 1987; Pakenham et al., 2004; Stuart \& McGrew, 2009). It also showed adequate internal consistency in the present study $(\alpha=.85)$.

2.2.4. Internal resources (B). The Rosenberg Self-Esteem inventory (RSE: Rosenberg, 1965) was used as a measure of internal resources. It includes 10 items, with five positively worded and five negatively worded, which are rated on a 4-point scale. This scale has been reported to have high reliability with test-retest correlations between .82 and .88 , and Cronbach's $\alpha$ reported to be between .77 and .88 across a range of samples (e.g., see Blascovich \& Tomaka, 1993; Rosenberg, 1986). This measure has previously been used in surveys of parents of children with autism (Higgins et al., 2005). It showed poor reliability in the present study ( $\alpha=$ .57); however was retained based upon previous results and contribution towards answering the research question.

2.2.5. External resources (bB). The Multidimensional Scale of Perceived Social Support (MSPSS: Zimet, Dahlem, Zimet, \& Farley, 1988) was used to measure social support of 
significant other, family, and friends. Items on this scale are rated on a 7-point Likert scale. A total score was calculated for this scale, with higher ratings indicating greater social support. This scale has been reported to have good test-retest reliability $(r=.85)$ and high internal consistency $(\alpha=.92)$ by the scale's creators (Zimet et al., 1988). It also showed high internal consistency in the present study $(\alpha=.96)$.

2.2.6. Appraisal of stressor (C). The Family Implications of Childhood Disability Scale (FICD: Trute \& Hiebert-Murphy, 2002) was used to measure the negative and positive implications of having a child with a disability. This scale contains 15 items including negative, (10 items) and positive implications (5 items) subscales. Items are rated on a 4-point Likert scale. A total score was calculated for each subscale. The authors of this scale report good internal consistency for each subscale (negative: $\alpha=.88$; positive, $\alpha=.71$ ). Minor changes to wording were made in terminology to be more inclusive to a range of social groups ("God" changed to "Spiritual Beliefs"; "spouse" changed to "partner") and to this sample ("disabled child" altered to "child with ASD"). In the present study, the scale with these minor alterations retained its acceptable internal consistency (negative: $\alpha=.89$; positive, $\alpha=.74$ ).

2.2.7. Coping strategies (cC). The Brief COPE (Carver, 1997) was used to measure the coping styles used by parents. This scale contains 28 items, which are rated on a 4-point Likert scale. The four dimensions of coping (active avoidance, problem-focused, positive coping, and religious/denial coping) were used for the present study (see Hastings, Kovshoff, Brown, et al., 2005, p.382 for descriptions of scale items). The authors found acceptable to good reliability for each of these scales $(\alpha=.68-.82)$, and we too found these scales to have acceptable reliability (active avoidance $\alpha=.73$, problem-focused $\alpha=.72$, positive coping $\alpha=.64$, religious $/$ denial $\alpha=$ 
.73). For each participant, a score on each dimension was obtained by summing ratings on each item within that dimension.

2.2.8. Individual outcome (X). Two measures of individual outcome were assessed including parenting stress and individual psychological distress (i.e. mood symptoms). The Parenting Stress Index: Short Form (PSI-SF: Abidin, 1995b) was used as a measure of overall stress associated with parenting. This short-form is a direct derivative of the widely-used PSI, and contains 36 items, which are divided into three subscales with 12 items each (Parental Distress, Parent-Child Dysfunctional Interaction, and Difficult Child) as well as a total score (sum of three subscales) which was used for the present study. Each item is scored on a 5-point scale. The authors report that test-retest reliability over a 6-month period ranged from .68 -.84, with acceptable to good internal consistency $(\alpha=.80-.91)$, and high correlations with the original form total score and subscales $(r=.49-.94)$. The total score likewise showed good internal consistency in the present study $(\alpha=.95)$.

The Depression Anxiety Stress Scale- 21 (DASS-21: Lovibond \& Lovibond, 1995) was used to assess individual psychological distress. It is a short-form of the DASS-42. This shorter form includes 21 items which are rated on a 4-point Likert scale. This scale is a dimensional measure of mood symptoms for the past week across three subscales which include depression ( 7 items), anxiety ( 7 items), and stress ( 7 items). As recommended by the authors, the total subscale scores were calculated by summing and doubling scores, and were used in the present study. Total scores were also categorised into severity (normal, mild, moderate, severe, or extremely severe) based on normative data in the manual (Lovibond \& Lovibond, 1995). This scale has been found to have good internal consistency for each subscale with Cronbach's $\alpha$ between .82 and.93 (e.g., 
Henry \& Crawford, 2005). Subscales likewise showed good internal consistency in the present study (Depression, $\alpha=.92 ;$ Anxiety, $\alpha=.87$; Stress, $\alpha=.89$ ).

2.2.9. Relationship outcome (X). The Marital Satisfaction Questionnaire (MSQ: Norton, 1983) was used to assess global relationship satisfaction. It includes 6 items, with 5 general items, which are rated on a 7-point Likert scale as well as a global rating of overall satisfaction which is rated on a 10-point scale. Possible scores range from 6 to 45 , with a score equal to or less than 29 considered clinically significant (Heyman, Sayers, \& Bellack, 1994). We made a slight modification to this scale by replacing "Marital" and "Spouse" to "Relationship and "Partner" to be inclusive of parents in this study who may not be married. This scale showed good internal consistency in the present study $(\alpha=.96)$.

2.2.10. Family outcome (X). The Impact on Family Scale (IFS: Stein \& Riessman, 1980) was used to assess family psychological distress. It is a 24-item self-report measure, with items rated on a 4-point Likert scale. It includes four factors, financial (4 items), familial/social (9 items), personal strain (6 items), and mastery (5 items), as well as a total score (sum of scales with mastery reverse-scored) which was used for the present study. Minor changes were made to wording to adapt this scale to this sample (e.g., "illness" replaced with "ASD”). Like Stuart and McGrew (2009), we too recoded individual item responses so that higher scores indicated higher levels of distress for ease of interpretation. The authors of this scale report that this scale has adequate internal consistency $($ alpha $=.88)$ and test-rest reliability $(r=.72)$. Acceptable internal consistency was retained in the present study $(\alpha=.89)$. 


\section{Results}

\subsection{Descriptive Statistics}

Demographic characteristics of questionnaire respondents and their children are provided in Table 1. Data suggested that survey respondents had a mean age of just below 40, varied in work status, were a high income group ( $47.6 \%$ earning $\$ 80,000$ or more), and that the vast majority were married. Similar numbers of male and female parents responded. The mean age of the children associated with this study was close to 50 months, almost $80 \%$ of the children were males, and almost $60 \%$ were diagnosed with Autistic Disorder.

[Insert Table 1 here]

Additionally, the results in Table 2 offer means, standard deviations and sample size for both the input (i.e., the measures of factors predicted to be associated with outcomes) and the outcome (i.e., measures of psychological distress on the family) variables used in this study.

[Insert Table 2 about here]

3.1.1. Individual outcome. Two measures of individual outcome were investigated, parenting stress (the stress associated with parenting), and psychological distress (general mood symptoms) including depression, anxiety, and stress. With respect to parenting stress on average parents $(M=112.3, S D=24.4)$ scored above the $95^{\text {th }}$ percentile compared to normative data, and the majority of individual parents (72\%) scored in the clinical range (at or above the 85th percentile, see Abidin, 1995b). With respect to psychological distress, parents in the present study reported on average reported elevated levels of distress across all three areas with depression mean scores in the moderate range $(M=14.6, S D=11.6)$ in the moderate range, and anxiety $(M=9.0, S D=10.1)$ and (general) stress mean scores $(M=18.2, S D=11.1)$ in the mild range. 
3.1.2. Relationship outcome. The average rating of parents was in the non-clinical range ( $M$ $=30.90, S D=9.1$, range $7-45$ ), however $60.5 \%$ of individual parents scored within the clinical range.

3.1.3. Family outcome. No clinical cut-offs were available for this measure, however the present sample scored statistically similarly $(M=63.3, S D=15.4)$ to ratings obtained for mothers of children with a chronic illness $(M=59.04, S D=9.48$; Stein \& Riessman, 1980).

\subsection{Associations between Individual, Relational and Family Outcome $(X)$ and $A B C$} Variables

Correlation analysis was used on this sample to determine if the hypothesis being tested was correct: That higher symptom severity (ASD symptoms and/or challenging behaviour), greater pile-up of life demands (additional stressful events), negative appraisals of caring for a child with ASD, and greater use of active-avoidant coping styles would be linked with increased psychological distress across each level of the family system (individual, relationship, and family). Power analysis using G*Power 3.1 (Faul, Erdfelder, Lang, \& Buchner, 2007) suggested insufficient power to compare across gender on variables (achieved power .35) or to split by gender for correlations, with achieved power of .58 to detect a large $(r=.50)$ effect. Hence, analyses were conducted for the sample as a whole. As missing data were a concern, Little's (1988) Missing Completely At Random test was completed, $\chi^{2}(302, N=43)=297.51, p=0.55$. This indicated that data were missing completely at random; as a result multiple imputations were run using SPSS 21 prior to subsequent analysis. Additionally, as inflation of the error rate was also a concern due to the multiple test comparisons, the initial alpha level of .05 was adjusted using the Holm-Bonferroni (1979) method. Results from the analysis are provided in Table 3 and in the discussion that follows. 
3.2.1. A. Symptom severity. Higher levels of ASD symptoms (i.e., SCQ total scores) were, in contrast to predictions, not significantly associated with higher levels of family distress including parenting stress, depression, anxiety and stress symptoms, nor relationship quality or negative impact on family as measured by the MSQ and IFS respectively, see Table 3.

However, as predicted, higher levels of challenging behaviour as measured by the SDQ were associated with higher levels of individual distress in terms of parenting stress which showed a large and significant effect $(r=.65, p=.000)$. However, higher levels of challenging behaviour were not significantly linked to depression, anxiety, or stress scores. Higher levels of challenging behaviour, as predicted, were also associated with higher levels of negative impact on family $(r=.66, p=.008)$, but were not associated with relationship quality.

[Insert Table 3 about here]

3.2.2. aA. Pile-up demands. Participants experienced moderate levels of additional stressors, endorsing an average of $5.63(S D=5.00$, range $0-19)$ additional stressors of a possible 50 potentially distressing life events as measured on the RSRRS. The average rating of distress per event was $2.95(S D=.81)$, indicating events were on average experienced with moderate distress. The total distress score (sum of ratings) was used as a measure of pile-up demands. As predicted, there was a strong positive relationship between pile-up demands and individual distress in terms of higher depression $(r=.45, p=.004)$, anxiety $(r=.58, p=.000)$, and stress symptoms $(r=.69, p=.000)$. Higher pile-up demands were moderately, but not significantly, associated with greater parenting stress. There was a positive relationship between greater pile-up demands and more negative impact on family, but again this was non-significant. There was a strong negative relationship between pile-up demands and relationship quality $(r=-$ 
$.58, p=.000)$, such that greater pile-up demands were associated with poorer relationship quality.

3.2.3. B. Internal resources (self-esteem). As predicted, higher self-esteem was associated with lower levels of individual distress on depression $(r=-.57, p=.000)$. This association was not found to be significant across any of the remaining individual nor relational and family variables.

3.2.4. bB. External resources (social support). As predicted, participants'scores on the MSPSS indicated that greater social support was associated with lower levels of individual distress across all individual level variables except anxiety, including depression $(r=-.47, p=$ $.001)$, stress $(r=-.53, p=.000)$, and parenting stress $(r=-.60, p=.000)$. Greater social support was also associated with better relationship quality $(r=.51, p=.001)$ and lower negative impact on family $(r=-.63, p=.000)$.

3.2.5. C. Appraisal of stressor. Endorsing more positive implications was linked to better relationship quality $(r=.43, p=.005)$. However, contrary to predictions, endorsement of positive implications was not significantly linked to lower levels of depression, anxiety, stress or parenting stress or family impact. However, the direction of the association for all of these variables was in the expected direction.

As predicted, endorsing more negative implications of having a child with ASD was associated with higher levels of individual distress on parenting stress $(r=.62, p=.000)$, as well as negative family impact $(r=.70, p=.000)$. However, in contrast to predictions, endorsing more negative implications of having a child with ASD was not associated with greater depression, anxiety, stress, or relationship quality. 
3.2.6. Cc. Coping strategies. As predicted, greater use of active-avoidance coping strategies were associated with higher levels of depression $(r=.56, p=.000)$, stress $(r=.44, p=$ $.005)$, and parenting stress $(r=.46, p=.004)$, see Table 3 . There was no significant association with active-avoidance coping and anxiety, relationship quality or with negative impact on family. Greater use of problem-focused coping or positive coping was not significantly linked to higher levels of individual, relationship or family level outcomes. Lastly, a greater use of religious/denial coping was linked to higher levels of individual distress in terms of depression symptoms $(r=.34, p=.026)$, but was not significantly linked to anxiety, stress, parenting stress, relationship quality, or negative impact on family.

\section{Discussion}

The present study investigated the applicability of the Double ABCX Model as a framework to understand the factors that lead to or reduce psychological distress in parents of young children with ASD attending early intervention. With respect to level of psychological distress, the findings of this study are largely consistent with prior research in regards to elevated mood symptoms and parenting stress, reduced relationship quality, and negative impact on family (Baker-Ericzén et al., 2005; Bristol, 1987; Bouma \& Schweitzer, 1990; Eisenhower et al., 2005; Konstantareas et al., 1992; Lee et al., 2009; Stuart \& McGrew, 2009). A key aim of this study was to identify factors that led to or reduced this psychological distress based on predictions from the Double ABCX Model. The most consistent and strongest predictors of psychological distress were pile-up of demands, social support, and the use of active-avoidant coping styles. Additionally, symptom severity in the form of challenging behaviour and negative appraisals were influential on parenting stress and negative impact on family, while positive appraisals were linked to better relationship quality. Greater use of religious coping was linked 
to higher depression ratings, while higher self-esteem was related to lower depression ratings. Overall, the model provided a useful framework for understanding critical influences on psychological distress at the individual, relationship, and family levels.

Consistent with previous research (e.g., Estes et al., 2009), greater pile-up of additional demands were associated with higher levels of individual distress in terms of depression, anxiety and stress symptoms, and lower relationship quality. Interestingly, greater pile-up of demands was not significantly linked to parenting stress or impact on family, and this may be because these measures linked specifically to the impact of caring for a child with ASD; whereas, individual distress and relationship quality were broader measures of adaptation related to everyday functioning and may be thus more heavily influenced by broader stressors. It may be that the additional demands the confluences of stressors bring, may overwhelm already-stretched resources. This finding highlights the importance for both practitioners and researchers, to evaluate not only the impact of the initial stressor (child's ASD/symptoms and challenging behaviour) and those that may arise from it, but also additional demands or stressful life events that the family may face such as those measured by the Revised Social Readjustment Rating Scale.

Family resources were found to be linked to outcomes as predicted by the model. The internal resource of self-esteem was significantly linked to the outcome of reduced depression only. Whether lower self-esteem is a cause or effect, or indeed has a transactional relationship with depression symptoms remains to be tested. A particularly important resource highlighted in the present study, however, was social support. Consistent with prior research on the buffering effect of social support (Boyd et al., 2002; Bristol, 1987; Ekas et al., 2010; Manning et al., 2010, Stuart \& McGrew, 2009), parents who reported higher social support reported better outcomes 
on all measures except one (anxiety). Outcomes included lower depression, stress, and parenting stress, a reduction in negative impact on family, and a higher relationship quality.

There are a number of potential explanations for why social support appears to be a most important resource to parents. First, social support may be an important resource to counteract the demands of caring for a child with ASD through either providing emotional or practical support. Parents commonly report a lack of sufficient formal services and supports (e.g., Woodgate, Ateah, \& Secco, 2008) and social support may help families to fill these needs in informal ways. Second, social support may prevent or mitigate unhelpful coping mechanisms such as avoiding public situations due to concerns around children's behaviour leading to social isolation, commonly reported by families of children with ASD (e.g., Woodgate et al., 2008). Third, social support may facilitate other helpful coping mechanisms such as developing positive appraisals, with some studies showing, for example, being around other parents with positive perceptions of their child helps to develop positive attributions (e.g., Singer et al., 1999). Some evidence for this proposal is found in the link between positive appraisals and higher relationship quality also found in this study, although pathway analysis was not possible due to the sample size. Given the impact of social support on all outcomes except for anxiety, it is important for professionals to discuss families' levels of social support and support parents to develop and maintain social supports, for example through parent groups

In this study, the strategies parents used to respond and cope with stressors affected their outcomes. In particular, the coping strategy of active avoidance appeared to be particularly unhelpful, with higher use significantly correlated with depression, stress, and parenting stress. This finding was consistent with previous research (e.g., Hastings, Kovshoff, \& Brown, et al., 2005; Stuart \& McGrew, 2009). This is also consistent with the broader literature on coping that 
suggests avoidant strategies may be of assistance in the short-term for overwhelming or unexpected crises, but they become a risk factor when used for longer-term or chronic stressors (see, for example, the review by Roth \& Cohen, 1986). Avoidant strategies may prevent the individual from confronting the stressor or its consequences directly. In the case of caring for a child with ASD, using active-avoidance to cope with, for example, challenging behaviour, may lead to an increase in challenging behaviour and have a greater negative impact by preventing the family from accessing beneficial resources such as social support.

Religious/denial coping was linked to higher levels of depression in line with Hasting, Kovshoff, and Brown et al. (2005), but in contrast to other studies that found positive impacts of religious coping (Manning et al., 2010). This seeming discrepancy may be explained by the inclusion of denial items in both in the present study, and the research undertaken by Hasting, Kovshoff, and Brown, et al. (2005). Denying stressors may lead to them becoming more serious thus leading to more negative outcomes (i.e., higher depression ratings). These findings, linking avoidant and denial coping strategies to more negative outcomes, emphasise the importance of supporting families to develop and use adaptive coping strategies in order to minimise the need to use maladaptive strategies such as avoidance or denial. Early intervention providers may support families in engaging in more active coping by providing supports and training around coping with key stressors for their family, such as linking parents with financial support or training to manage stressors.

The way families interpreted, defined, and understood (i.e., appraised) caring for a child with ASD also affected their outcomes. In line with Stuart and McGrew (2009), having more positive appraisals of caring for a child with ASD was significantly linked to better relationship quality, while negative appraisals were correlated with higher parenting stress and negative impact on 
family. In line with a cognitive perspective, it may be that the impact of stressors is mediated or moderated by the way the stressor is perceived by families. This suggests, particularly when the stressors themselves cannot be changed (e.g., child's diagnosis) that family outcomes may be improved by focusing on appraisals of events. Thus cognitive behaviour therapy may be of assistance for parents experiencing particular difficulties with stress or negative impact on families. In addition, as discussed earlier, exposure to parents with more positive appraisals may also help parents to shape their appraisals to more positive, helpful appraisals (e.g., Singer et al., 1999).

Consistent with Manning et al., (2010), challenging behaviour severity, but not severity of ASD symptoms, was linked to greater parenting stress and negative impact on family. This is in line with previous research linking challenging behaviour to increased stress and negative impact on families (Benson, 2010; Eisenhower et al., 2005; Estes et al., 2009; Manning et al., 2010). However, this is in contrast to previous research that did find links with level of ASD symptoms (e.g., Abbeduto et al., 2004; Manning et al., 2010; Osborne et al., 2008b). This discrepancy, may be related to the fact that all families in the present study were participating in an early intervention service which included a focus on improving children's communication and social skills (see Paynter et al., 2012). Therefore, these families may have better understood or felt optimistic about gains in these critical skill areas and a corresponding reduction in ASD symptoms (i.e. they could understand and accept these symptoms as part of their child).

Previous research has suggested that challenging behaviours, rather than ASD symptoms, may be more stigmatising for both the child and family, given children's typically "normal" appearance and members of the community responding negatively or judgementally to challenging behaviours (see, for example, Higgins et al., 2005). This may then lead to parental 
stress and negative impacts on family, such as parents avoiding social situations and becoming increasingly isolated to cope with such responses (e.g., Woodgate et al., 2008). There may also be transactional relationships between challenging behaviour and parenting stress, in that not only does challenging behaviour lead to greater parent stress, but greater parenting stress may also increase a child's propensity for challenging behaviour. For example, greater parent stress may affect parenting behaviours such as setting poor limit setting (see Osborne et al., 2008a). Conversely, learning strategies to more effectively manage challenging behaviours, or more effective coping strategies in the presence of challenging behaviours, is likely to be beneficial in reducing parenting stress and negative impact on family. As such, parents engaged in early intervention services should be provided with access to specific support and training around challenging behaviour, which could be offered by early intervention providers via support groups, psychologists, or other professionals trained in evidence-based approaches.

\subsection{Limitations and Future Research}

Further research is needed to more thoroughly examine the impacts of symptom severity, greater pile-up of life demands, negative appraisals of caring for a child with ASD, and greater use of active-avoidant coping styles and their links with increased psychological distress across each level of the family system with this population. Such work should utilise larger sample sizes to investigate the relative regression weightings of each potential contributing factor. Moreover, path analysis or structural equation modelling could be undertaken to test the goodness of fit of the ABCX model to explain family adaptation for families of young children attending an autism-specific early intervention program. Additionally, longitudinal or intervention studies could also help to elucidate the direction of effects (such as between parenting stress and child challenging behaviours). This increased understanding should provide 
an opportunity for early intervention services to identify, target, and develop preventative strategies to reduce the potential of future families realising negative outcomes. Additionally, these same larger samples of both males/females could be used to investigate whether factors influencing burden differ across gender. There is a good deal of literature that explores the differences in experiences between males and females in parenting a child with exceptionality (Krauss, 1993) and these differences would be worth exploring in order to better uncover the ways in which these variables interact. These causal pathways may assist in better understanding the targets for intervention to improve outcomes for both parents of, and children with ASD.

\subsection{Summary of Implications}

Findings of elevated negative outcomes, consistent with the broader literature, have clear implications for early intervention service providers and other professionals working with families during this period. While these data provide only preliminary results, the indications are that families of young children involved with early intervention are at risk for psychological distress at individual, relationship, and family levels. Thus, family adaptation should be assessed upon entry to early intervention services in order to identify families who may benefit from additional support. Support may be needed to ameliorate the impact of caring for a child with ASD and associated challenges such as pile-up of additional demands or challenging behaviour, which may be a focus for parent training, given its strong links with a range of outcomes. Services should also support parents to develop their social support networks as these mechanisms appear to be a most important resource. In addition, support should also be given support to develop parental adaptive coping strategies and appraisals (i.e., positive appraisals) in order to reduce the need for reliance on maladaptive strategies such as active-avoidance. Thus, the results of this study should be used to improve the services that benefit not only family 
wellbeing, but also support children's development and gains in early intervention, given links between parent stress and outcomes (e.g., Osborne et al., 2008a; Robbins et al., 1991).

\subsection{Conclusions}

This study provides promising preliminary data to support the utility of the ABCX model of family adaptation to families with a young child in early intervention, and is consistent with previous studies using this model with parents of children with ASD who were at different life stages, at time of diagnosis, at school age, and a broad range of ages (Bristol, 1987; Manning et al., 2010; Stuart \& McGrew, 2009). Further research is needed with larger samples to explore the relative contributions of individual variables as well as any moderators or mediators in these relationships. Longitudinal research to explore directions of effects would also be of benefit. The ABCX Model would seem to provide a useful framework for uniting a range of variables to better understand adaptation in families with a young child with ASD who is receiving early intervention services. This model has the potential to provide professionals with a framework to better understand individual parent's strengths and needs in order to assist them, and their children, to achieve their optimum level of functioning and outcome from early intervention.

\section{Acknowledgements}

We wish to thank the parents and caregivers who shared their experiences with us and gave their time to complete questionnaire packages. We would also like to thank the AEIOU staff who assisted in recruitment. Thank you also to the Australian Government Department of Housing, Community Services, and Indigenous Affairs (FaHSCSIA) for their financial support provided for the AEIOU program. Thank you finally to Associate Professor Helen Heussler and Dr James Scott (Research Advisory Group members, AEIOU Foundation) for their helpful suggestions on an earlier version of this paper. 


\section{References}

Abbeduto, L., Seltzer, M. M., Shattuck, P., Krauss, M. W., Orsmond, G., Murphy, M. M. (2004). Psychological well-being and coping in mothers of youths with autism, Down syndrome, or Fragile X syndrome. American Journal on Mental Retardation, 109(3), 237-254.

Abidin, R. R. (1995a). Manual for the Parenting Stress Index (3rd ed.). Charlottesville, VA: Pediatric Psychology Press.

Abidin, R. R. (1995b). Parenting Stress Index [Short Form]. Odessa, FL: Psychological Assesment Resources Inc.

Allik, H., Larsson, J.-O., \& Smedje, H. (2006). Health-related quality of life in parents of schoolage children with Asperger syndrome or high-functioning autism. Health and Quality of Life Outcomes, 4(1), 1-8.

APA. (2000). Diagnostic and statistical manual of mental disorders : DSM-IV-TR (4th, text revision. ed.). Washington, DC: American Psychiatric Association.

Baker-Ericzén, M. J., Brookman-Frazee, L., \& Stahmer, A. (2005). Stress levels and adaptability in parents of toddlers with and without autism spectrum disorders. Research and Practice for Persons with Severe Disabilities, 30(4), 194-204.

Baker, B. L., Blacher, J., \& Olsson, M. B. (2005). Preschool children with and without developmental delay: behaviour problems, parents' optimism and well-being. Journal of Intellectual Disability Research, 49(8), 575-590.

Benson, P. R. (2010). Coping, distress, and well-being in mothers of children with autism. Research in Autism Spectrum Disorders, 4(2), 217-228. 
Berument, S., Rutter, M., Lord, C., Pickles, A., \& Bailey, A. (1999). Autism screening questionnaire: Diagnostic validity. The British Journal of Psychiatry, 175(5), 444-451. doi: 10.1192/bjp.175.5.444

Blacher, J., \& McIntyre, L. L. (2006). Syndrome specificity and behavioural disorders in young adults with intellectual disability: Cultural differences in family impact. Journal of Intellectual Disability Research, 50(3), 184-198.

Blascovich, J., \& Tomaka, J. (1993). Measures of self-esteem. In J. P. Robinson, P. R. Shaver, \& L. S. Wrightsman (Eds.), Measures of personality and social psychological attitudes (pp. 115-160). Ann Arbor: Institute for Social Research.

Bouma, R., \& Schweitzer, R. (1990). The impact of chronic childhood illness on family stress: A comparison between autism and cystic fibrosis. Journal of Clinical Psychology, 46(6), $722-730$.

Boyd, B. A. (2002). Examining the relationship between stress and lack of social support in mothers of children with autism. Focus on Autism and Other Developmental Disabilities, $17(4), 208-215$.

Bristol, M. M. (1987). Mothers of children with autism or communication disorders: Successful adaptation and the double ABCX model. Journal of Autism and Developmental Disorders, 17(4), 469-486.

Carver, C. (1997). You want to measure coping but your protocol's too long: Consider the brief cope. International Journal of Behavioral Medicine, 4(1), 92-100.

Centers for Disease Control and Prevention. (2012). Prevalence of Autism Spectrum Disorders — Autism and Developmental Disabilities Monitoring Network, 14 Sites, United States, 
2008. Morbidity and Mortality Weekly Report (MMWR) Surveillance Summaries, 61 (SS03), 1-19.

Charman, T., \& Howlin, P. (2003). Research into early intervention for children with autism and related disorders: Methodological and design issues. Autism, 7(2), 217-225.

Eisenhower, A. S., Baker, B. L., \& Blacher, J. (2005). Preschool children with intellectual disability: Syndrome specificity, behaviour problems, and maternal well-being. Journal of Intellectual Disability Research, 49(9), 657-671.

Ekas, N., Lickenbrock, D., \& Whitman, T. (2010). Optimism, social support, and well-being in mothers of children with autism spectrum disorder. Journal of Autism and Developmental Disorders, 40(10), 1274-1284.

Estes, A., Munson, J., Dawson, G., Koehler, E., Zhou, X.-H., \& Abbott, R. (2009). Parenting stress and psychological functioning among mothers of preschool children with autism and developmental delay. Autism, 13(4), 375-387.

Goodman, R. (1997). The Strengths and Difficulties Questionnaire: A research note. Journal of Child Psychology and Psychiatry, 38(5), 581-586.

Goodman, S., Rouse, M., Connell, A., Broth, M., Hall, C., \& Heyward, D. (2011). Maternal depression and child psychopathology: A meta-analytic review. Clinical Child and Family Psychology Review, 14(1), 1-27. doi: 10.1007/s10567-010-0080-1

Hastings, R., \& Brown, T. (2002). Behavior problems of children with autism, parental selfefficacy, and mental health. American Journal of Mental Retardation, 107(3), 222-232.

Hastings, R., Kovshoff, H., Brown, T., Ward, N. J., Espinosa, F. D., \& Remington, B. (2005). Coping strategies in mothers and fathers of preschool and school-age children with autism. Autism, 9(4), 377-391. 
Hastings, R., Kovshoff, H., Ward, N., Espinosa, F., Brown, T., \& Remington, B. (2005). Systems analysis of stress and positive perceptions in mothers and fathers of pre-school children with autism. Journal of Autism and Developmental Disorders, 35(5), 635-644.

Henry, J. D., \& Crawford, J. R. (2005). The short-form version of the Depression Anxiety Stress Scales (DASS-21): Construct validity and normative data in a large non-clinical sample. British Journal of Clinical Psychology, 44, 227-239.

Heyman, R. E., Sayers, S. L., \& Bellack, A. S. (1994). Global marital satisfaction versus marital adjustment: An empirical comparison of three measures. Journal of Family Psychology, $8(4), 432-446$.

Higgins, D. J., Bailey, S. R., \& Pearce, J. C. (2005). Factors associated with functioning style and coping strategies of families with a child with an autism spectrum disorder. Autism, $9(2), 125-137$.

Hobson, C., \& Delunas, L. (2001). National norms and life-event frequencies for the revised social readjustment rating scale. International Journal of Stress Management, 8(4), 299314.

Holm, S. (1979). A simple sequentially rejective multiple test procedure. Scandinavian Journal of Statistics, 6(2), 65-70.

Holmes, T. H., \& Rahe, R. H. (1967). The Social Readjustment Rating Scale. Journal of Psychosomatic Research, 11(2), 213 - 218.

Kelly, J. B. (2000). Children's adjustment in conflicted marriage and divorce: A decade review of research. Journal of the American Academy of Child \& Adolescent Psychiatry, 39(8), 963-973. 
Konstantareas, M. M., Homatidis, S., \& Plowright, C. M. S. (1992). Assessing resources and stress in parents of severely dysfunctional children through the Clarke modification of Holroyd's questionnaire on resources and stress. Journal of Autism and Developmental Disorders, 22(2), 217-234.

Krauss, M. W. (1993). Child-related and parenting stress: Similarities and differences between mothers and fathers of children with disabilities. American Journal of Mental Retardation, 97(4), 393-404.)

Lee, G. K., Lopata, C., Volker, M. A., Thomeer, M. L., Nida, R. E., Toomey, J. A., et al. (2009). Health-related quality of life of parents of children with high-functioning autism spectrum disorders. Focus on Autism and Other Developmental Disabilities, 24(4), 227239.

Little, R. J. A. (1988). A test of missing completely at random for multivariate data with missing values. Journal of the American Statistical Association, 83(404), 1198 - 1202.

Lord, C., Wagner, A., Rogers, S., Szatmari, P., Aman, M., Charman, T., et al. (2005). Challenges in evaluating psychosocial interventions for autistic spectrum disorders. Journal of Autism and Developmental Disorders, 35(6), 695-708.

Lovibond, S. H., \& Lovibond, P. F. (1995). Manual for the Depression Anxiety Stress Scales (2nd. ed.). Sydney: Psychology Foundation.

Makrygianni, M. K., \& Reed, P. (2010). A meta-analytic review of the effectiveness of behavioural early intervention programs for children with Autistic Spectrum Disorders. Research in Autism Spectrum Disorders, 4(4), 577-593. 
Manning, M., Wainwright, L., \& Bennett, J. (2010). The Double ABCX Model of Adaptation in racially diverse families with a school-age child with autism. Journal of Autism and Developmental Disorders, 41(3), 1-12.

McCubbin, H. I., \& Patterson, J. M. (1983). The family stress process - The double ABCX model of adjustment and adaptation. Marriage \& Family Review, 6(1), 7-37.

Norton, R. (1983). Measuring marital quality: A critical look at the dependent variable. Journal of Marriage and Family, 45(1), 141-151.

Olson, D. H., Sprenkle, D. H., \& Russell, C. S. (1979). Circumplex model of marital and family systems 1: Cohesion and adaptability dimensions, family types, and clinical applications. Family Process, 18, 3-28.

Osborne, L., McHugh, L., Saunders, J., \& Reed, P. (2008a). Parenting stress reduces the effectiveness of early teaching interventions for autistic spectrum disorders. Journal of Autism and Developmental Disorders, 38(6), 1092-1103.

Osborne, L. A., McHugh, L., Saunders, J., \& Reed, P. (2008b). A possible contra-indication for early diagnosis of autistic spectrum conditions: Impact on parenting stress. Research in Autism Spectrum Disorders, 2(4), 707-715.

Pakenham, K. I., Samios, C., \& Sofronoff, K. (2005). Adjustment in mothers of children with Asperger syndrome. Autism, 9(2), 191-212.

Pakenham, K. I., Sofronoff, K., \& Samios, C. (2004). Finding meaning in parenting a child with Asperger syndrome: correlates of sense making and benefit finding. Research in Developmental Disabilities, 25(3), 245-264. 
Paynter, J., Riley, E., Beamish, W., Heussler, H., \& Scott, J. (2013). The AEIOU early intervention program: An effectiveness study. Paper presented at the Asia Pacific Autism Conference, Adelaide, Australia.

Paynter, J., Scott, J., Beamish, W., Duhig, M., \& Heussler, H. (2012). A pilot study of the effects of an Australian centre-based early intervention program for children with autism. The Open Pediatric Medicine Journal, 6, 7-14.

Ramisch, J. (2010). Marriage and family therapists working with couples who have children with autism. Journal of Marital and Family Therapy, no-no. doi: 10.1111/j.17520606.2010.00210.x

Randall, P., \& Parker, J. (1999). Supporting the families of children with autism. Chichester: Wiley.

Redington, C. J., Kysela, G. M., \& McDonald, L. (1995). Adaptation and functioning in families of children with special needs: A rural perspective. Exceptionality Education Canada, $5(2), 57-85$.

Reyno, S. M., \& McGrath, P. J. (2006). Predictors of parent training efficacy for child externalizing behavior problems: A meta-analytic review. Journal of Child Psychology and Psychiatry, 47(1), 99-111.

Robbins, F. R., Dunlap, G., \& Plienis, A. J. (1991). Family characteristics, family training, and the progress of young children with autism. Journal of Early Intervention, 15(2), 173184.

Rodrigue, J. R., Morgan, S. B., \& Geffken, G. (1990). Families of autistic children: Psychological functioning of mothers. Journal of Clinical Child Psychology, 19(4), 371379. 
Rosenberg, M. (1965). Society and the adolescent self-image. Princeton, NJ: Princeton University Press.

Rosenberg, M. (1986). Conceiving the self. Krieger: Malabar, FL.

Roth, S., \& Cohen, L. J. (1986). Approach, avoidance, and coping with stress. American Psychologist, 41(7), 813-819.

Rutter, M., Bailey, A., \& Lord, C. (2003). Social Communication Questionnaire. Los Angeles, CA: Western Psychological Services.

Sanders, J. L., \& Morgan, S. B. (1997). Family stress and adjustment as perceived by parents of children with autism or Down syndrome: Implications for intervention. Child \& Family Behavior Therapy, 19(4), 15-32.

Singer, G. H. S., Marquis, J., Powers, L. K., Blanchard, L., Divenere, N., Santelli, B., et al. (1999). A multi-site evaluation of parent to parent programs for parents of children with disabilities. Journal of Early Intervention, 22, 217-229.

Stein, R. E. K., \& Riessman, C. K. (1980). The development of an impact-on-family scale: Preliminary findings. Medical Care, 18(4), 465-472.

Stuart, M., \& McGrew, J. H. (2009). Caregiver burden after receiving a diagnosis of an autism spectrum disorder. Research in Autism Spectrum Disorders, 3(1), 86-97.

Trute, B., \& Hiebert-Murphy, D. (2002). Family adjustment to childhood developmental disability: A measure of parent appraisal of family impacts. Journal of Pediatratic Psychology, 27(3), 271-280.

Turnbull, A. P., \& Turnbull, H .R. (2001). Families, professionals, and exceptionality: Collaborating for empowerment ( $4^{\text {th }}$ ed.). Columbus, OH: Merrill. 
Weiss, M. J. (2002). Hardiness and social support as predictors of stress in mothers of typical children, children with autism, and children with mental retardation. Autism, 6(1), 115130.

Woodgate, R. L., Ateah, C., \& Secco, L. (2008). Living in a world of our own: The experience of parents who have a child with autism. Qualitative Health Research, 18(8), 1075-1083.

Wray, J., Silove, N., \& Knott, H. (2005). Language disorders and autism. Medical Journal of Australia, 182(7), 354-360.

Zimet, G. D., Dahlem, N. W., Zimet, S. G., \& Farley, G. K. (1988). The multidimensional scale of perceived social support. Journal of Personality Assessment, 52(1), 30 - 41. 


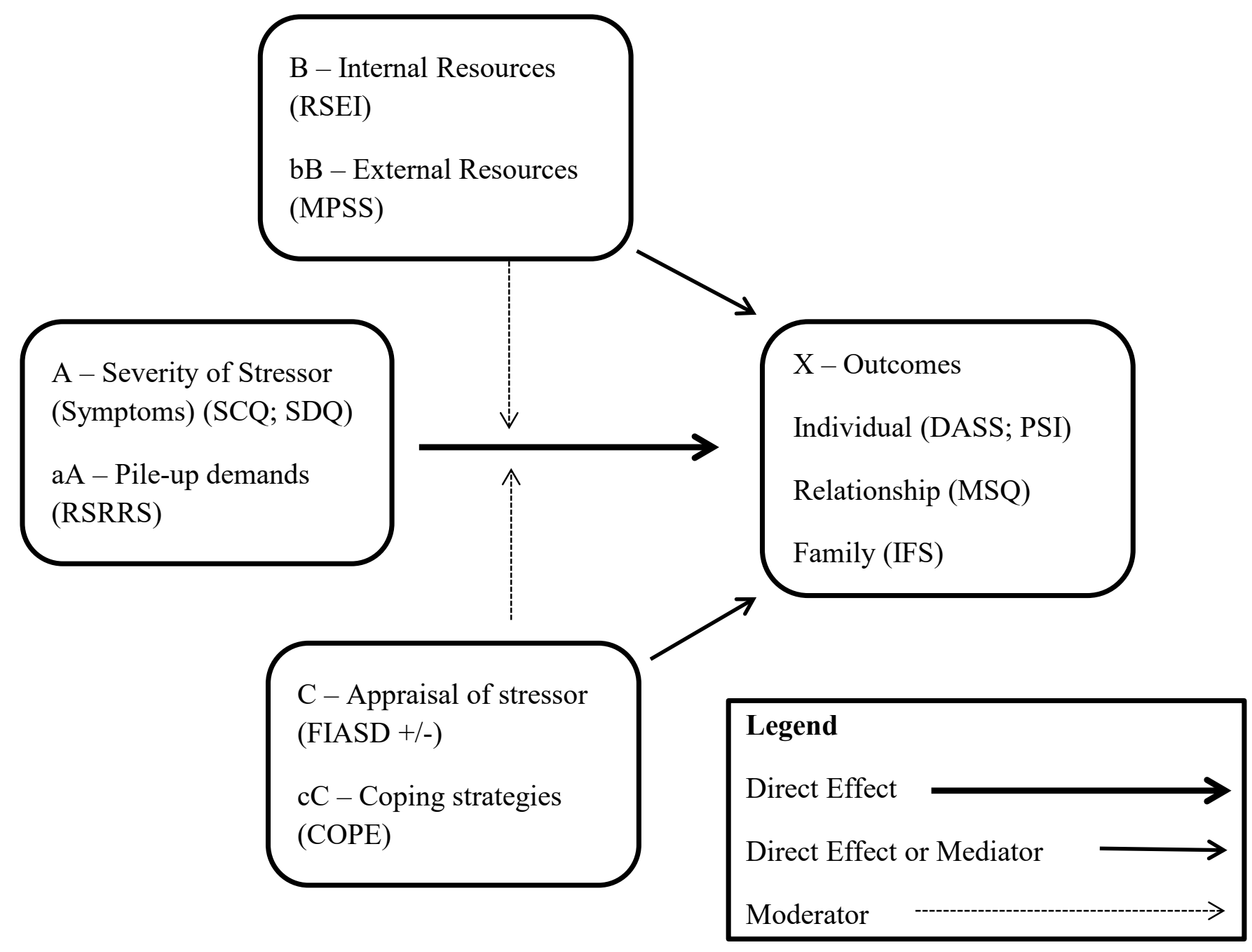

Figure 1 Modified Double ABCX Model (based on McCubbin \& Patterson, 1983; Stuart \& McGrew, 2009). 


\section{Tables}

Table 1

Demographic Characteristics of Caregivers and Clinical and Demographic Characteristics of their Children with ASD

\begin{tabular}{lc}
\hline \multicolumn{1}{c}{ Demographic Characteristic } & Value \\
\hline Age of parent (years) & 37.4 \\
Mean & 7.9
\end{tabular}

Gender $(\%)$

Female

58.1

Male

41.9

Work Status $(\%)$

Full time paid employment $\quad 27.9$

Part time paid employment $\quad 9.3$

$\begin{array}{ll}\text { Casual paid employment } & 7.0\end{array}$

$\begin{array}{lc}\text { Self employed } & 11.6\end{array}$

Out of work and currently looking for work $\quad 2.3$

Out of work but not currently looking for work 4.7

Full time home duties $\quad 25.6$

$\begin{array}{ll}\text { Full time student } & 2.3\end{array}$

Retired $\quad 2.3$

Unable to work $\quad 7.0$

Relationship Status (\%)
Married

In a relationship but living apart $\quad 4.7$

Single/never married $\quad 7.0$

Living with partner/de facto $\quad 11.6$

$\begin{array}{ll}\text { Widowed } & 2.3\end{array}$

$\begin{array}{ll}\text { Separated } & 4.7\end{array}$

Families approximate total yearly income (\%)

$\$ 6,001$ to $\$ 14,000 \quad 4.8$

$\$ 14,001$ to $\$ 26,000 \quad 7.1$

$\$ 26,001$ to $\$ 34,000 \quad 4.8$

$\$ 34,000$ to $\$ 50,000 \quad 11.9$

$\$ 50,001$ to $\$ 80,000 \quad 21.4$

$\$ 80,001$ or more $\quad 47.6$

Negative income/loss $\quad 2.3$

$\begin{array}{ll}\text { Declined answer } & 2.3\end{array}$ 
Age of child (months)

Mean

SD

Gender of child (\%)

Female

Male

Diagnosis (\%)

Autistic Disorder

Asperger's Disorder

PDD-NOS

Other e.g."ASD"
49.4

9.2

18.6

81.4

58.1

4.7

9.3

27.9 
Table 2

Means and Standard Deviations for Study Variables

\begin{tabular}{lccc}
\hline \multicolumn{1}{c}{ Variable } & Mean & SD & N \\
\hline A. SCQ & 18.9 & 6.6 & 35 \\
A. SDQ $\sim$ total difficulties & 17.1 & 4.7 & 41 \\
aA. RSRRS & 18.4 & 16.7 & 37 \\
B. RSE & 18.4 & 5.4 & 40 \\
bB. MSPSS & 56.9 & 18.3 & 40 \\
C. FICD $(+)$ & 11.8 & 3.4 & 40 \\
C. FICD $(-)$ & 30.2 & 7.7 & 40 \\
cC. COPE $\sim$ avoid & 16.6 & 4.8 & 40 \\
cC. COPE $\sim$ problem & 19.8 & 3.9 & 42 \\
cC. COPE $\sim$ positive & 14.5 & 3.1 & 39 \\
cC. COPE $\sim$ denial & 5.6 & 1.9 & 41 \\
X. PSI & & & 37 \\
X. DASS $\sim$ depression & 112.3 & 24.4 & 41 \\
X. DASS $\sim$ anxiety & 14.6 & 11.6 & 41 \\
X. DASS $\sim$ stress & 9.0 & 10.1 & 41 \\
X. MSQ & 18.2 & 11.1 & 39 \\
X. IFS & 30.9 & 9.1 & 34 \\
\hline
\end{tabular}


Table 3

Correlations between ABC (Explanatory) Variables and X (Outcome) Variables

\begin{tabular}{|c|c|c|c|c|c|c|}
\hline \multirow[b]{4}{*}{ ABC Variables } & \multicolumn{6}{|c|}{ Outcomes (X) } \\
\hline & \multicolumn{4}{|c|}{ Individual Distress } & \multirow{2}{*}{$\begin{array}{c}\text { Relationship } \\
\text { MSQ }\end{array}$} & \multirow{3}{*}{$\begin{array}{c}\text { Family } \\
\text { IFS } \\
\text { Negative } \\
\text { Impact } \\
\text { on } \\
\text { Family }\end{array}$} \\
\hline & & DASS & & PSI & & \\
\hline & Depression & Anxiety & Stress & $\begin{array}{c}\text { Parenting } \\
\text { Stress }\end{array}$ & $\begin{array}{c}\text { Relationship } \\
\text { Quality }\end{array}$ & \\
\hline \multicolumn{7}{|l|}{ Symptom Severity } \\
\hline $\begin{array}{r}\text { ASD Symptoms } \\
\text { (A.SCQ) }\end{array}$ & .31 & .09 & .08 & .50 & -.08 & .50 \\
\hline $\begin{array}{r}\text { Challenging } \\
\text { Behaviour } \\
\text { (A.SDQ) }\end{array}$ & .35 & .16 & .30 & $.65^{*}$ & -.26 & $.66^{*}$ \\
\hline Pile-up Demands & & & & & & \\
\hline $\begin{array}{r}\text { Stressful life } \\
\text { events } \\
(\text { aA.RSRRS })\end{array}$ & $.45^{*}$ & $.58 *$ & $.69^{*}$ & .30 & $-.58^{*}$ & .34 \\
\hline $\begin{array}{l}\text { Internal } \\
\text { Resources }\end{array}$ & & & & & & \\
\hline $\begin{array}{r}\text { Self-esteem } \\
\text { (B.RSEI) }\end{array}$ & $-.57 *$ & -.40 & -.43 & -.40 & .45 & -.27 \\
\hline $\begin{array}{l}\text { External } \\
\text { Resources }\end{array}$ & & & & & & \\
\hline $\begin{array}{r}\text { Social support } \\
\text { (bB.MSPSS) }\end{array}$ & $-.47 *$ & -.39 & $-.53 *$ & $-.60 *$ & $.51 *$ & $-.63 *$ \\
\hline Appraisals & & & & & & \\
\hline $\begin{array}{r}\text { Positive } \\
\text { (C.FIASD }+)\end{array}$ & -.39 & -.26 & -.42 & -.39 & $.43^{*}$ & -.41 \\
\hline $\begin{array}{r}\text { Negative } \\
\text { (C.FIASD-) }\end{array}$ & .43 & .36 & .38 & $.62 *$ & -.14 & $.70 *$ \\
\hline $\begin{array}{l}\text { Coping Strategies } \\
\text { (cC.COPE) }\end{array}$ & & & & & & \\
\hline Active avoidance & $.56^{*}$ & .31 & $.44^{*}$ & $.46^{*}$ & -.08 & .24 \\
\hline Problem-focused & .03 & .20 & .37 & -.18 & .31 & -.10 \\
\hline Positive & .02 & .08 & .01 & -.01 & .41 & .07 \\
\hline Religious/Denial & $.34 *$ & .32 & .18 & .17 & -.07 & .07 \\
\hline
\end{tabular}

* Significant after Holm-Bonferroni correction 